\title{
Epidemiological features and specificities of HCV infection: a hospital-based cohort study in a university medical center of Calabria region
}

\author{
MC Liberto*, N Marascio, E Zicca, G Matera \\ From Second Workshop of the Regional Study Group on HCV in the Calabria Region (Southern Italy). The \\ virus-host-therapy pathway in HCV disease management: from bench to bedside in the era of Directly Act- \\ ing Antivirals \\ Catanzaro, Italy. 16 October 2012
}

\begin{abstract}
The epidemiological status of HCV in Europe, and in particular in Mediterranean countries, is continuously evolving. The genotype distribution is related to improvement of healthcare conditions, expansion of intravenous drug use and immigration. We review and characterize the epidemiology of the distribution of HCV genotypes within Calabria, an area of Southern Italy. We focus on the pattern of distinct HCV genotype changes over the last 16 years; particularly subtype $1 \mathrm{~b}$ and genotype 4 . We collected data by evaluating a hospital-based cohort of chronic hepatitis $C$ patients; in addition, we report an update including new patients enrolled during last eight months.
\end{abstract}

\section{Introduction}

Hepatitis $\mathrm{C}$ virus (HCV) triggers worldwide chronic liver diseases, as cirrhosis and hepatocellular carcinoma (HCC). HCV infection represents the most important cause of liver transplantation in developed countries.

Despite the decline of the viral transmission rates, due to eradication of transfusion-associated infections and improvement in health-care-related standards, HCVrelated morbidity and mortality continue to rise and, due to slow disease progression, many patients are still at risk to progress to severe liver diseases [1]. For this reason prevention of $\mathrm{HCV}$ infections as well as improved knowledge of $\mathrm{HCV}$ infection epidemiology are particularly noteworthy.

$\mathrm{HCV}$ genotyping is an important approach in the management of HCV RNA positive patients and it is useful to understand the epidemiology of the virus with respect to the demographic characteristics of patients, liver disease grade, risk factors and source of infection. Genotyping has

\footnotetext{
* Correspondence: mliberto@unicz.it

Department of Health Sciences, Institute of Microbiology, University "Magna Graecia" of Catanzaro, 88100, Catanzaro, Italy
}

also been used to found HCV geographical distribution: subtype $1 \mathrm{~b}$ is spreading worldwide, subtype $3 \mathrm{a}$ is clustering in Europe and North America and genotype 4 appears endemic in Middle East and Central Africa. It is already known that the prevalence of $\mathrm{HCV}$, in a particular area, can be unstable and $\mathrm{HCV}$ changing pattern occurs because of several factors, as high rates of mutation in viral genome, drug pressure and migration of infected people to countries where a more sensitive population is established.

On this HCV changing pattern, surveillance studies have been carried out in several European regions [2,3].

Since 1997, our group studied distribution of HCV genotypes within Calabria, a region of Southern Italy, by evaluating a hospital-based cohort of chronic hepatitis $\mathrm{C}$ patients. This mini-review summarizes published data on the epidemiology of HCV within this area, focusing on the pattern of distinct $\mathrm{HCV}$ genotype changes over the last 16 years, particularly subtype $1 \mathrm{~b}$ and genotype 4. In addition, an update of the last eight months will be addressed. 


\section{HCV spread in the Mediterranean countries of Europe}

In Europe, the epidemiology of HCV infection is rapidly changing and prevalence, as well as risk factors and genotype distribution exhibit significant geographic and temporal differences. In Northern and Central Europe the $\mathrm{HCV}$ prevalence is ranging from $0.2 \%$ (in the Netherlands) to $1.2 \%$ (in France) [2], virus is mainly transmitted by intravenous drug use (IDU) and the most prevalent infections are found among patients $30-50$ years old. In countries of the Mediterranean area of Europe the overall prevalence ranges between $2.5 \%$ and $3.5 \%$ [2], spread via blood products as well as IDU-related infections have been determined. Most importantly, immigration is leading to changes in HCV epidemiology and in the distribution of HCV genotypes. In Spain HCV prevalence is among the highest in Europe, with high rate of genotype 3 (mainly among IDUs) while the increasing rate of genotype 4 has been reported to be linked to IDU and immigration $[4,5]$.

Differences in prevalence of HCV infection have been observed in Turkey, where higher rates are reported in regions near the Black Sea when compared with other areas; the genotype $1 \mathrm{~b}$ was ranging between 75 and $90 \%$ in chronic infected patients $[1,6,7]$. In Turkey, the non-hospitalized childbirth or invasive and poor-hygiene standard medical procedures may increase the risk of transmission of HCV [1]. In Greece, another country in the Mediterranean region of Europe, the prevalence of the disease is high $(6-10 \%)$ in some isolated areas and it is mainly due to unsafe parenteral injections or invasive medical procedures. Genotype 1 is predominant among chronically infected people, genotype 3 is rising and 15\% of infections are caused by genotype $4[8,9]$.

In Italy, the $\mathrm{HCV}$ epidemiology has some specificity. In a HCV seroprevalence and molecular epidemiology study, performed in a sample of the Italian general population, Ansaldi et al., [10] showed a north-south prevalence gradient and confirmed that Central and Southern Italy are hyper endemic areas. In this study HCV subtype $1 \mathrm{~b}$ was the most prevalent in all geographical areas followed by subtypes $2 \mathrm{c}, 4 \mathrm{a} / 4 \mathrm{~d}, 3 \mathrm{a}$ and $1 \mathrm{a}$. The prevalence of subtype $1 \mathrm{~b}$ increased with age.

Overall, risk factors are related to hospital-based transmission, healthcare-related or IDU transmission and, concerning age distribution, a high prevalence of $\mathrm{HCV}$ in the elderly has been established. Different studies reported on the genotype distribution of $\mathrm{HCV}$ in Italy [11-15]. Genotype $1 \mathrm{~b}$ appeared to be the most frequent type of infection [13-15] followed by genotype 2, which is more common in Italy than in other parts of Europe. Likewise, in a small epidemiological study, carried out in a Southern Italian town, HCV subtype $2 \mathrm{a}$ has been reported to be predominant with respect to subtype $1 \mathrm{~b}$ [11]. Changes in the prevalence of $\mathrm{HCV}$ genotypes among Italian injection drug users, in relation to the time of infection, have been reported [12], namely a decline in genotype 3 has been observed, while genotype 4 has become more frequent. The prevalence of HCV type 4 increased in Southern [16], and Central Italy [14]. Genotype 5 and $6 \mathrm{HCV}$ were rarely found as well as mixed infections with more genotypes [1].

\section{HCV in Calabria region: epidemiological features}

In our first investigation we report data on changes in the prevalence of hepatitis $C$ virus genotype 4 in Calabria, Southern Italy. In particular we evaluated prevalence of circulating $\mathrm{HCV}$ genotypes, as well as relationships between genotype, sex and age in sera from $3273 \mathrm{HCV}$ positive patients collected from January 1997 until February 2001 [16].

The main findings on genotype distribution showed that HCV 1b was the most common subtype (1744 cases, $53.3 \%$ ) followed by $2 \mathrm{a} / 2 \mathrm{c}$ (857 cases, $26.2 \%)$ and both were associated with older age. This distribution was similar to other studies regarding the prevalence of HCV genotypes in Italy and Western Europe.

Genotype 4 was the fifth most prevalent genotype observed, just after $3 \mathrm{a}$ and 1a subtypes. Analyzing the distribution of the HCV genotype 4 during three consecutive periods of 17, 19 and 13 months, within the full observation period, we reported an early increase (January 1997-May 1998) of the genotype 4 (3.3\% versus 1.3\%),in comparison to prevalence findings previously observed by Guadagnino et al., [17]. Data obtained from serum samples, collected from June 1998 until December 1999 and from January 2000-February 2001, indicated a further increase in prevalence of genotype $4.3 .7 \%$ and $4.7 \%$ respectively).

Therefore, on HCV positive sera collected from January 1997 until February 2001, we verified a fourfold increased prevalence of HCV genotype 4. While in this period other authors found type 4 to be related to IDU in younger individuals [18], by contrast our data showed that spreading of genotype 4 in the Calabria region was associated with older age, when compared to genotype $3 \mathrm{a}$ and $1 \mathrm{a}$, and associated with a younger group of patients when compared with genotype $1 \mathrm{~b}$. Moreover, HCV genotype 4infected patients denied having traveled to endemic areas and most of them lived in rural areas. We assumed that such an increase could be partially due to previous undervaluation of the real prevalence of genotype 4 in the Calabria. Moreover, we hypothesized that this HCV genotype could be endemic in some restricted and isolated areas of Calabria. 
Recently we updated data on the distribution of $\mathrm{HCV}$ genotypes, by evaluating a hospital-based cohort of 2153 chronic hepatitis $\mathrm{C}$ patients, collected prospectively among subjects attending University Hospital of Catanzaro, Calabria, Southern Italy [19]. The rates of HCV genotypes during two consecutive periods, from 2001 to 2005 and from 2006 to 2011, according to age and gender were considered. Concerning the eleven-year period of observation, subtype $1 \mathrm{~b}$ was predominant (49.2\%), followed by subtype $2 \mathrm{a} / 2 \mathrm{c}$, genotypes 3 and 4 , with a rate of $22.4 \%, 7.4 \%$ and $6.2 \%$ respectively.

Still at present subtype $1 \mathrm{~b}$ is the most common HCV type associated with risk factors such as blood/blood derivatives transfusion and surgical procedures. Subtype 1binfected patients are $>65$ years old, accordingly with Ansaldi et al., who reported a transmission pattern found in adults older than 60 years, due to health care-related practices in the past and characterized by subtypes $1 \mathrm{~b}$ and 2c infections [10]. As in other European reports, our data show that $1 \mathrm{~b}$ prevalence decreased over the past eleven years and this finding is mainly due to the improved health standards that reduced $\mathrm{HCV}$ transmission.

When data of the two consecutive periods were examined, a higher percentage of HCV infection in $>65$ age group (33.7\% versus 41.2\%) was observed. Between 2001 and 2005, the distribution of subtype $1 \mathrm{~b}$ was similar in 56 - 65 and >65 age groups, while between 2006 and 2011 data showed an increased distribution in $>65$ age group with respect to 56 - 65 age group. Interestingly, during the 2006-2011 period HCV genotype 4 was mostly present in patients 56 - 65 years old (31.6\%), while two different peaks, during the $2006-2011$ period, were observed: $27.6 \%$ among the 36 - 45 years old and $24.1 \%$ in patients over 65 years old.

Therefore, during the 2006 - 2011 period, statistical analysis of HCV patient age, stratified by genotypes, showed a slight but significant increase in the median age of subtype $1 \mathrm{~b}$, subtype $2 \mathrm{a} / 2 \mathrm{c}$ and genotype $3 \mathrm{HCV}$ infected subjects, while genotype 4 patients exhibited a decrease in the median age during the same period studied.

Genotype 4 is to date the fourth prevalent genotype in our area and the observation regarding the shift of the highest prevalence of genotype 4 towards younger age group (36 - 45) during 2006 - 2011, sounds as a challenge for epidemiologists. Probably this trend could be related to increased sexual risk behavior.

\section{Update of HCV epidemiology in Calabria}

The update of our epidemiology investigation includes the new subjects enrolled as a hospital - based cohort of $\mathrm{HCV}$-infected patients during last eight months. The age of patients with genotype/subtype 3 was significantly lower than age of subjects with genotypes/subtypes $1 \mathrm{~b}$ ( $\mathrm{p}<0.05$ Tukey post-hoc test). Also the age of patients with genotype/subtype $2 \mathrm{a} / 2 \mathrm{c}$, 4 and 1 was higher than the age of subjects with genotype 3, without a statistical significance (Figure 1). Dealing with gender distribution of genotypes/subtypes HCV we found a significant $(\mathrm{p}<$ 0.05 by $\chi^{2}$ test) predominance of females among the $2 \mathrm{a} /$ $2 \mathrm{c}$-positive subjects, by contrast the male gender was significantly associated with genotype 3 ( $\mathrm{p}<0.05$ by $\chi^{2}$ test). Regarding the viral load the subtypes $2 \mathrm{a} / 2 \mathrm{c}$ and $1 \mathrm{a}$ shared the highest values; the genotypes/subtypes $1 \mathrm{~b}, 1$ and 3 exhibit the medium values, and genotypes 4 and 2 showed a lower amount of viral load (Table 1).

\section{Conclusion}

HCV epidemiology shows a high variability across Mediterranean countries of Europe and Italy. The evaluation of chronic $\mathrm{HCV}$ prevalence, genotype distribution and risk factors for transmission, represent a great challenge, which will pay off in achievement of efficient measures for hepatitis $C$ prevention. Nation-specific strategies could be applied in different countries to decrease spreading of $\mathrm{HCV}$ infection. The most representative change in $\mathrm{HCV}$ genotype prevalence, observed in our region, has been reported to be an increase in genotype 4. Appropriated interventions are warranted to control genotype 4 epidemics because this genotype is associated with a great risks of complications (cirrhosis and HCC) [20] and a poor response to standard treatment. Such interventions can now be difficult because the ways of transmission are expanding, including not only IDU, but also, probably, sexual risk behaviors.

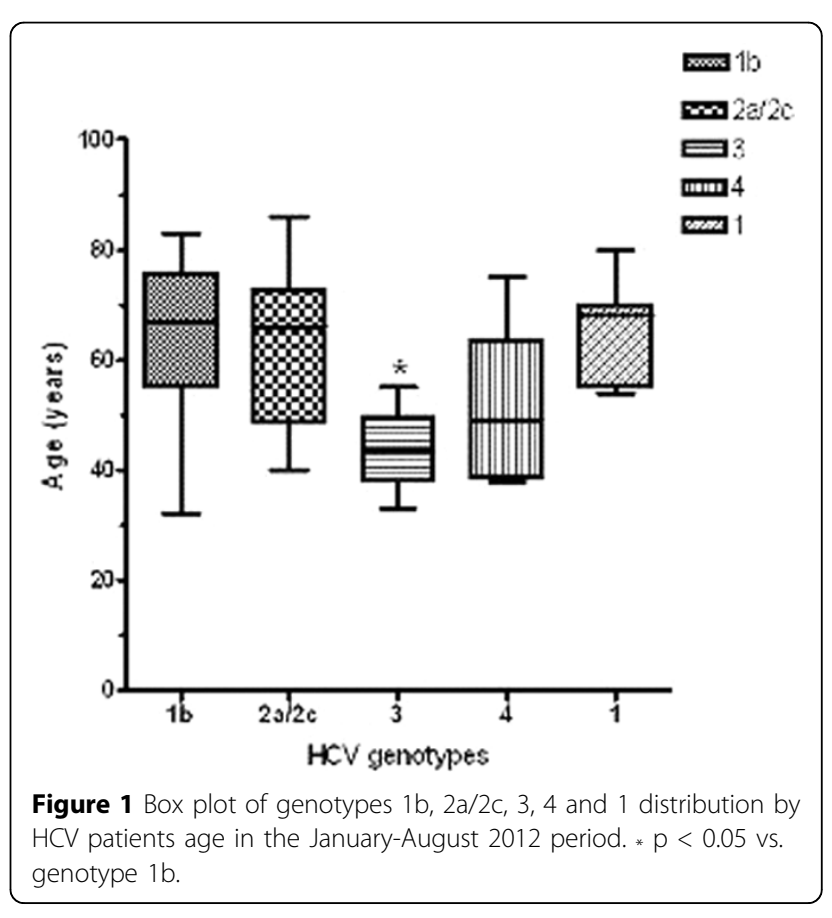


Table 1 HCV genotypes/subtypes distribution, gender and viral load of 67 patients from January to August 2012.

\begin{tabular}{|c|c|c|c|c|c|c|c|c|}
\hline \multirow[t]{2}{*}{ HCV genotypes/ subtypes } & \multirow[t]{2}{*}{ No. of isolates } & \multirow[t]{2}{*}{ Percentage (\%) } & \multicolumn{4}{|c|}{ Gender } & \multirow[t]{2}{*}{$P$ value } & \multirow{2}{*}{$\begin{array}{c}\log _{10} \text { HCV-RNA }(\mathrm{UI} / \mathrm{ml}) \\
\text { Mean } \pm \text { SEM }\end{array}$} \\
\hline & & & Male & (\%) & Female & (\%) & & \\
\hline 1 & 7 & 10.5 & 2 & 28.6 & 5 & 71.4 & $>0.05$ & $6.6 \pm 6.2$ \\
\hline $1 b$ & 29 & 43.3 & 19 & 65.5 & 10 & 34.5 & $>0.05$ & $6.7 \pm 6.4$ \\
\hline $1 \mathrm{a}$ & 4 & 5.9 & 3 & 75.0 & 1 & 25.0 & $>0.05$ & $7.0 \pm 6.6$ \\
\hline 2 & 1 & 1.5 & 0 & 0.0 & 1 & 100.0 & $>0.05$ & $3.3 \pm 0.0$ \\
\hline $2 a / 2 c$ & 17 & 25.4 & 6 & 35.3 & 11 & 64.7 & $<0.05$ & $7.1 \pm 6.7$ \\
\hline 3 & 4 & 5.9 & 4 & 100.0 & 0 & 0.0 & $<0.05$ & $3.7 \pm 6.3$ \\
\hline 4 & 5 & 7.5 & 3 & 60.0 & 2 & 40.0 & $>0.05$ & $3.2 \pm 5.9$ \\
\hline Total & 67 & 100 & 37 & 55.2 & 30 & 44.8 & & $3.9 \pm 6.3$ \\
\hline
\end{tabular}

\section{List of abbreviations used}

HCV: Hepatitis C Virus; IDU: Intravenous Drug Use; HCC: hepatocellular carcinoma.

\section{Declarations}

Publication of this supplement was partly supported by an unrestricted grant provided by Roche. The articles were independently prepared by the authors with no input from Roche. Roche were not involved in selecting the articles for the supplement.

\section{Acknowledgements}

This article has been published as part of BMC Infectious Diseases Volume 12 Supplement 2, 2012: Proceedings of the Second Workshop of the Regional Study Group on HCV in the Calabria Region (Southern Italy). The virus-hosttherapy pathway in HCV disease management: from bench to bedside in the era of Directly Acting Antivirals. The full contents of the supplement are available online at http://www.biomedcentral.com/bmcinfectdis/ supplements/12/S2.

\section{Competing interests}

The authors declare that they have no competing interests.

Published: 12 November 2012

\section{References}

1. Cornberg M, Razavi HA, Alberti A, Bernasconi E, Buti M, Cooper C, Dalgard O, Dillion JF, Flisiak R, Forns X, Frankova S, Goldis A, Goulis I, Halota W, Hunyady B, Lagging M, Largen A, Makara M, Manolakopoulos S, Marcellin P, Marinho RT, Pol S, Poynard T, Puoti M, Sagalova O, Sibbel S, Simon K, Wallace C, Young K, Yurdaydin C, et al: A systematic review of hepatitis $C$ virus epidemiology in Europe, Canada and Israel. Liver Int 2011, 31(Suppl 2):30-60.

2. Esteban Jl, Sauleda S, Quer J: The changing epidemiology of hepatitis C virus infection in Europe. J Hepatol 2008, 48:148-162.

3. Lavanchy D: Evolving epidemiology of hepatitis C virus. Clin Microbiol Infect 2011, 17:107-115.

4. Echevarría JM, León P, Pozo F, Avellón A: Follow-up of the prevalence of hepatitis C virus genotypes in Spain during a nine-year period (19962004). Enferm Infecc Microbiol Clin 2006, 24:20-25.

5. Fernández-Arcás N, López-Siles J, Trapero S, Ferraro A, Ibáñez A, Orihuela F, Maldonado J, Alonso A: High prevalence of hepatitis $C$ virus subtypes $4 c$ and $4 \mathrm{~d}$ in Malaga (Spain): phylogenetic and epidemiological analyses. J Med Virol 2006, 78:1429-1435.

6. Altuglu I, Soyler I, Ozacar T, Erensoy S: Distribution of hepatitis C virus genotypes in patients with chronic hepatitis $C$ infection in Western Turkey. Int I Infect Dis 2008, 12:239-244.

7. Keskın F, Çıftçı S, Türkoğlu S, Badur S: Transmission routes for chronic hepatitis C and its relation with HCV genotypes. Turk J Gastroenterol 2010, 21:396-400.

8. Savvas SP, Koskinas J, Sinani C, Hadziyannis A, Spanou F, Hadziyannis SJ: Changes in epidemiological patterns of HCV infection and their impact on liver disease over the last 20 years in Greece. J Viral Hepat 2005, 12:551-557.
9. Raptopoulou M, Touloumi G, Tzourmakliotis D, Nikolopoulou G, Dimopoulou M, Giannoulis G, Vasiliadis T, Skoutelis A, Anagnostou O, Hatzis G, Manolakopoulos S: Significant epidemiological changes in chronic hepatitis $C$ infection: results of the nationwide HEPNET-GREECE cohort study. Hippokratia 2011, 15:26-31.

10. Ansaldi F, Bruzzone B, Salmaso S, Rota MC, Durando P, Gasparini R, Icardi G: Different seroprevalence and molecular epidemiology patterns of hepatitis C virus infection in Italy. J Med Virol 2005, 76:327-332.

11. Cozzolongo R, Osella AR, Elba S, Petruzzi J, Buongiorno G, Giannuzzi V, Leone G, Bonfiglio C, Lanzilotta E, Manghisi OG, Leandro G, NUTRIHEP Collaborating Group, Donnaloia R, Fanelli V, Mirizzi F, Parziale L, Crupi G, Detomaso P, Labbate A, Zizzari S, Depalma M, Polignano A, Lopinto D, Daprile G: Epidemiology of HCV infection in the general population: a survey in a southern Italian town. Am J Gastroenterol 2009, 104:2740-2746.

12. Sereno $S$, Perinelli $P$, Laghi $V$ : Changes in the prevalence of hepatitis $C$ virus genotype among Italian injection drug users-relation to period of injection started. J Clin Virol 2009, 45:354-357.

13. Pizzillo P, Almasio PL, Ferraro D, Craxi A, Di Stefano R: HCV genotypes in Sicily: is there any evidence of a shift? J Med Virol 2009, 81:1040-1046.

14. Cenci M, Massi M, Alderisio M, De Soccio G, Recchia O: Prevalence of hepatitis $C$ virus (HCV) genotypes and increase of type 4 in central Italy: an update and report of a new method of HCV genotyping. Anticancer Res 2007, 27:1219-1222.

15. Dal Molin G, Ansaldi F, Biagi C, D'Agaro P, Comar M, Crocè L, Tiribelli C, Campello $C$ : Changing molecular epidemiology of hepatitis $C$ virus infection in Northeast Italy. J Med Virol 2002, 68:352-356.

16. Matera G, Lamberti A, Quirino A, Focà D, Giancotti A, Barreca GS, Guadagnino V, Liberto MC: Changes in the prevalence of hepatitis $C$ virus (HCV) genotype 4 in Calabria, Southern Italy. Diagn Microbiol Infect Dis 2002, 42:169-173.

17. Guadagnino V, Stroffolini T, Rapicetta M, Costantino A, Kondili LA, MennitiIppolito F, Caroleo B, Costa C, Griffo G, Loiacono L, Pisani V, Focà A, Piazza M: Prevalence, risk factors, and genotype distribution of hepatitis $C$ virus infection in the general population: a community-based survey in southern Italy. Hepatology 1997, 26:1006-1011.

18. Sánchez-Quijano A, Abad MA, Torronteras R, Rey C, Pineda JA, Leal M, Macias J, Lissen E: Unexpected high prevalence of hepatitis $C$ virus genotype 4 in Southern Spain. J Hepatol 1997, 27:25-29.

19. Marascio N, Matera G, Quirino A, Giancotti A, Barreca GS, Lamberti AG, Caroleo B, Liberto MC, Focà A: Eleven-year distribution pattern of hepatitis C virus in southern Italy. J Pathog 2012, 2012:631095.

20. Kamal SM, Nasser IA: Hepatitis C genotype 4: what we know and what we don't yet know. Hepatology 2008, 47:1371-1383.

\section{doi:10.1186/1471-2334-12-S2-S4}

Cite this article as: Liberto et al.: Epidemiological features and specificities of HCV infection: a hospital-based cohort study in a university medical center of Calabria region. BMC Infectious Diseases 2012 12(Suppl 2):S4. 